\title{
Neurologic Manifestations in Human Immunodeficiency Virus Infection / Acquired Immunodeficiency Syndrome
}

From 1981 when acquired immunodeficiency syndrome (AIDS) was first reported (1,2), through mid-1996, 1.4 million cases of AIDS have been reported worldwide. The actual number may be 4 to 5 times this figure. The cumulative number of persons with human immunodeficiency virus (HIV) infection is estimated to be about 20 million. The impact of the HIV/ AIDS epidemic in the United States has been most dramatically demonstrated by national mortality data (3). In 1992, death due to HIV infection became the top leading cause of death among men aged 25-44 years in the United States, and the death rate due to AIDS still continues to increase. The condition in subsaharian Africa is undoubtedly much more serious although reliable data are not available; this will likely be the case in South-eastern Asia in 2,000's.

\section{See also $\mathrm{p} 175$.}

HIV infection is complicated by a variety of opportunistic infections, and a considerable portion of the patients present with central nervous system (CNS) and peripheral nervous system symptoms. Neurologic complications consist of opportunistic infection such as cerebral toxoplasmosis, cryptococcal meningitis and progressive multifocal leukoencephalopathy (PML), opportunistic neoplasms including primary CNS lymphoma and metastatic lymphoma, AIDS dementia and subacute encephalitis probably due to HIV infection itself, and other secondary conditions such as metabolic, toxic and miscellaneous complications of systemic diseases such as sepsis, strokes and hypoxic encephalopathy (4).

In the very early stage of acute HIV infection (primary infection), a variety of CNS disorders have been described (511). These include meningitis, focal or diffuse encephalitis, ataxia and myelopathy either alone or together with peripheral nervous system abnormalities. These disorders are usually monophasic, and most patients recover spontaneously within a few weeks. The cerebrospinal fluid (CSF) often shows a lymphocyte-predominant pleocytosis with a slight elevation in protein concentration.

In the so-called asymptomatic phase, development of demyelinating neuropathies is not rare, especially in the late asymptomatic phase. These neuropathies resemble chronic inflammatory demyelinating polyneuropathy or acute demyelinating polyneuropathy (Guillain-Barré syndrome). Even in neurologically asymptomatic patients, studies of CSF have shown some abnormality including increased cell count, protein and isolation of HIV (12-15).
In patients with a CD 4 count of less than 400 cells $/ \mu 1$, herpes zoster and mononeuritis multiplex may appear. Nervous system involvement in late phase HIV infection is very common. These include AIDS dementia complex, cryptococcal meningitis, toxoplasmosis, cytomegalovirus encephalitis, herpes encephalitis, lymphoma and metabolic/toxic encephalopathies. These complications usually appear when the CD4 count is below 50 cells $/ \mu$ l. Anti-HIV agents such as zidovudine, didanosine and zalcitabine may cause peripheral neuropathy as an adverse reaction to the agent.

In this issue of Internal Medicine, Nakagawa et al (16) described neurologic manifestation of AIDS among Japanese patients. According to their study, the incidence of neurologic manifestations among patients with AIDS was $28.7 \%$, and that of AIDS dementia was $11.8 \%$, the data being comparable to those from other countries. Interestingly, the incidence of neurologic manifestations among hemophiliac patients was lower than that among patients who contracted HIV through sexual contact. The difference may be due to the difference of medical care received. Hemophiliac patients with HIV infection usually visit their hospitals regularly, and receive anti-HIV chemotherapy, prophylaxis against opportunistic infections and get early diagnosis and treatment for complications. These medical care steps may reduce the risk of involvement of nervous system.

Very recently, the clinical availability of new anti-HIV agents has greatly expanded, allowing combination therapy. Combinations of reverse transcriptase inhibitors and/or protease inhibitors have been clearly shown to be very potent and beneficial clinically. Neurological manifestations which markedly decrease QOL of the patients and shorten their survival will be reduced by using appropriate anti-HIV agents in combination, and by appropriate prophylaxis and treatment of opportunistic infections involving the central or peripheral nervous system. However, AIDS dementia complex will eventually develop because of the mutagenecity and the limited permeability of anti-HIV agents to the blood-brain barrier. Therefore, development of anti-HIV agents highly permeable to the blood-brain barrier is awaited.

Satoshi Kimura, MD Department of Infection Control and Prevention, The First Department of Internal Medicine, Faculty of Medicine University of Tokyo 


\section{References}

1) Gottlieb MS, et al. Pneunocystis carinii pneumonia and mucosal candidiasis in previously healthy homosexual men: evidence of a new acquired cellular immunodeficiency. N Engl J Med 305: 1425, 1981.

2) CDC. Pneumocystis pneumonia - Los Angeles, MMWR 30: 250, 1981.

3) CDC. Uptake: Mortality attributable to HIV infection among persons aged 25-44 years - United States, 1994. MMWR 45: 121, 1996.

4) Price RW, Worley JM. Management of neurologic complications of HIV-1 infection and AIDS. in: Medical Management of AIDS. 4th ed., Sande MA, Volberding PA, Eds. W.B. Saunders Co., Philadelphia, 1995, p. 261.

5) Brew BJ. Medical management of AIDS patients: Central and peripheral nervous system abnormalities. Med Clin North Am 76: 63, 1992.

6) Calabrese LH, Proffitt MR, Levin KH, Yen-Lieberman B, Starkey C. Acute infection with the human immunodeficiency virus (HIV) associated with acute brachial neuritis and exanthematous rash. Arch Intern Med 107: 849, 1987.

7) Carne CA, Tedder RS, Smith A, et al. Acute encephalopathy coincident with seroconversion for anti-HTLV-III. Lancet 2: 1206, 1985.

8) Denning DW, Anderson J, Rudge P, Smith H. Acute myelopathy associated with primary infection with human immunodeficiency virus. $\mathrm{Br}$ Med J 294: 143, 1987.
9) Fox R, Eldred LJ, Fuchs EJ, et al. Clinical manifestations of acute infection with human immunodeficiency virus in a cohort of gay men. AIDS 1: 35, 1987.

10) Ho DD, Sarngadharan MG, Resnick L, Dimarzoveronese F, Rota TR, Hirsch MS. Primary human T-lymphotropic virus type III infection. Ann Intern Med 103: 880, 1985.

11) Piette AM, Tusseau F, Vignon $D$, et al. Acute neuropathy coincident with seroconversion for anti-LAV/HTLV-III. Lancet 1 (8485): 852, 1986 (letter).

12) Appleman ME, Marshall DW, Brey RL, et al. Cerebrospinal fluid abnormalities in patients without AIDS who are seropositive for the human immunodeficiency virus. J Infect Dis 158: 193, 1988.

13) Goswami K, Kaye S, Miller R, McAllister R, Tedder R. Intrathecal IgG synthesis and specificity of oligoclonal IgG in patients infected with HIV1 do not correlate with CNS disease. J Med Virol 33: 106, 1991.

14) Goudsmit J, deWolf F, Paul DA, et al. Expression of human immunodeficiency virus antigen (HIV-Ag) in serum and cerebrospinal fluid during acute and chronic infection. Lancet 2 (8500): 177, 1986.

15) Resnick L, Berger JR, Shapshak P, Tourtellotte WW. Early penetration of the blood-brain barrier by HIV. Neurology 38: 9, 1988.

16) Nakagawa $M$, Maruyama $Y$, Sugita $H$ and Osame $M$. Nationwide survey of neurologic manifestations of acquired immunodeficiency syndrome in Japan. Internal Med 36: 175, 1997. 